\title{
Comparing the effects of manual and ultrasonic instrumentation on root surface mechanical properties
}

\author{
Muhammad Sohail Zafar ${ }^{1}$
}

Correspondence: Dr. Muhammad Sohail Zafar

Email: drsohail_78@hotmail.com

\begin{abstract}
'Department of Restorative Dentistry, College of Dentistry, Taibah University, Madinah Al Munawwarah, Saudi Arabia
\end{abstract}

\section{ABSTRACT}

Objective: The aim of the current study is to analyze the surface profiles of healthy and periodontal-treated roots. In addition, manual and ultrasonic instrumentation methods have been compared in terms of surface mechanical properties of root surfaces including surface roughness, hardness, and elastic modulus. Materials and Methods: This study was conducted using extracted teeth that were randomly divided into two study groups ( 1 and 2). Root planing was performed using either Gracey curettes (Group 1) or ultrasonic scaler (Group 2). The noncontact profilometer was used to analyze surface roughness before and after root planing. A nanoindenter was used to analyze the surface mechanical properties. Results: The root planing treatment reduced the peak and valley heights hence decreasing the surface roughness. The average maximum height of peaks (Sp) and average maximum height of valleys (Sv) for control groups remain $83.08 \pm 18.47 \mu \mathrm{m}$ and $117.58 \pm 18.02 \mu \mathrm{m}$. The Sp was reduced to $32.86 \pm 7.99 \mu \mathrm{m}$ and $62.11 \pm 16.07 \mu \mathrm{m}$ for Groups 1 and 2, respectively. The $S v$ was reduced to $49.32 \pm 29.51 \mu \mathrm{m}$ for Group 1 and $80.87 \pm 17.99 \mu \mathrm{m}$ Group 2. The nanohardness and modulus of elasticity for cementum of the control group remain $0.28 \pm 0.13 \mathrm{GPa}$ and $5.09 \pm 2.67 \mathrm{GPa}$, respectively. Conclusions: Gracey curettes and ultrasonic scalers are capable of significantly reducing the roughness following root planing. Although Gracey curettes produced smoother surfaces than ultrasonic scalers, there was no significant difference.

Key words: Biomaterials, cementum, hardness, roughness

\section{INTRODUCTION}

There is a high prevalence of periodontal diseases among the populations of developed as well as developing countries. A majority of people suffer from gingivitis in response to bacterial plaque and progressing to periodontitis. Periodontitis is one of the common oral diseases that lead to the destruction of bone tissues and tooth loss. Timely and vigilant management of periodontal conditions is necessary to prevent the tooth loss due to irreversible bone destruction. The successful management is based on controlling the bacterial plaque and restricting

\begin{tabular}{|l|l|}
\hline \multicolumn{2}{|c|}{ Access this article online } \\
\hline Quick Response Code: \\
\hline
\end{tabular}

of further progression of the disease. ${ }^{[1]}$ A variety of treatment modalities such as conventional nonsurgical procedures (scaling-root planning), gingival curettage, ${ }^{[2]}$ laser therapy, ${ }^{[3]}$ and regenerative approaches ${ }^{[4,5]}$ can be indicated.

According to the American Academy of Periodontology, the health of periodontal tissue should be maintained using the least invasive approaches. ${ }^{[6]}$ Noninvasive periodontal treatment procedures including scaling, root planing, and oral

This is an open access article distributed under the terms of the Creative Commons Attribution-NonCommercial-ShareAlike 3.0 License, which allows others to remix, tweak, and build upon the work non-commercially, as long as the author is credited and the new creations are licensed under the identical terms.

For reprints contact: reprints@medknow.com

How to cite this article: Zafar MS. Comparing the effects of manual and ultrasonic instrumentation on root surface mechanical properties. Eur $\mathrm{J}$ Dent 2016;10:517-21.

DOI: $10.4103 / 1305-7456.195162$ 
hygiene maintenance are widely practiced by dentists and dental hygienists to manage the periodontal conditions. ${ }^{[2]}$ The scaling procedure involves eradication of plaque, calculus, and stains from the tooth crown and root surface. The root planing deals with removal of infected root cementum and dentin and preparing the root surfaces for reattachment of periodontal tissues. ${ }^{[7]}$ Although scaling and root planing is a very demanding technique, its role in controlling the gingival inflammation and bleeding index is well-accepted. ${ }^{[8]}$

There is a variable tissues response to nonsurgical treatments that are affected by various clinical factors such as severity of disease. In general, a significant reduction in the probing depth can be expected. ${ }^{[9]}$ Therefore, scaling and root planing is considered as the first line of treatment for the management of periodontal treatment targeting to prepare health and smooth root surface for the attachment of delicate healing gingival tissues. ${ }^{[10]}$ A variety of hand instruments and sonic and ultrasonic scalers are used for scaling and root planing. ${ }^{[2]}$ However, the surface texture and surface mechanical properties can be affected by the type of instrument. ${ }^{[11]}$ The aim of this study is to investigate the surface properties of healthy and periodontally affected roots. In addition, the effects of manual and ultrasonic instrumentation for mechanical debridement of roots (root planing) have been compared for surface properties.

\section{MATERIALS AND METHODS}

\section{Sample preparation}

This study was conducted using permanent human teeth extracted due to periodontal reasons. Freshly extracted teeth from anonymous patients were included in the study. Teeth with carious lesion or extraction trauma $(4 \%)$ in the cervical area were excluded from the study. For disinfection, all teeth were cleaned to remove tissue remnants and treated with sodium hypochlorite solution (5\%) for $24 \mathrm{~h}$. All disinfected specimens were washed using copious amount deionized distilled water. The crowns were removed and teeth were randomly divided into two groups and stored in normal saline until further [Figure 1].

All specimens were fixed in jaw models in mannequin heads (Dental care training manikin; Columbia Dentoform) in a way that only cervical third was available for instrumentation.

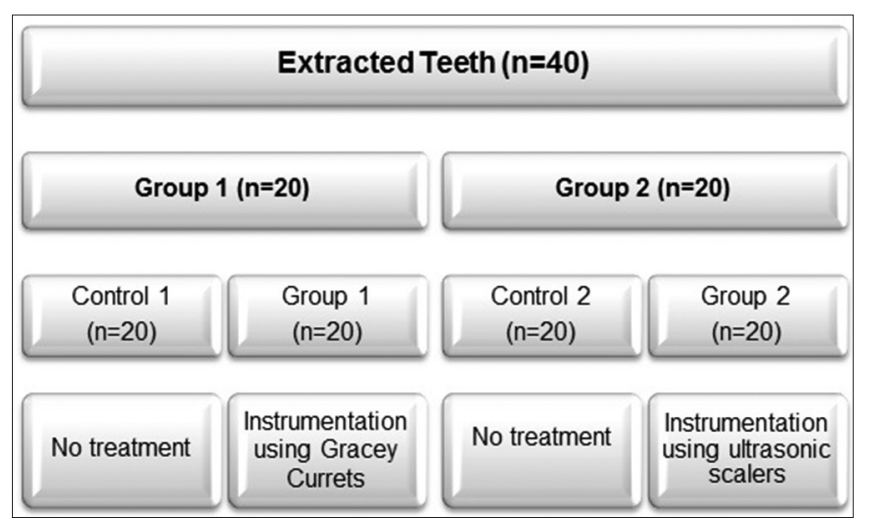

Figure 1: Description of study groups

\section{Periodontal instrumentation}

All samples (Groups 1 and 2) were characterized before any periodontal treatment and were considered as control (controls 1 and 2). The proximal surfaces (cervical third) were treated for periodontal instrumentation. For Group 1, samples $(n=20)$ were treated using Gracey curettes (11/12 Gracey Curettes, Hu-Friedy, Chicago, IL, USA). Scaling movements were performed using 15 strokes in apical-coronal direction for each surface under investigation. All samples were treated by one operator using the standard curettes angle and force applications. Each curette tip was used for five samples. Periodontal instrumentation for Group 2 samples $(n=20)$ was performed in exactly the same manners; however, Gracey curettes were replaced by ultrasonic scaler (PIEZO-soft ultrasonic scaler; KaVo Dental, Germany) equipped with PIEZO Scaler Tip 201. The ultrasonic instrumentation was performed using 15 strokes in apical to cervical direction using linear oscillations and a frequency of $30 \mathrm{kHz}$.

\section{Surface roughness profilometry}

The roughness profilometry was performed using a noncontact surface profiling system $\left(\right.$ Bruker $^{\circledR}$ 3D-optical ContourGT-K0) and methodology described previously. ${ }^{[12,13]}$ Briefly, specimens were mounted on the movable stage that can hold the sample in various angles and manually adjustable along $X, Y$, and $Z$ axes.

Once specimen focused, Vision $64^{\mathrm{TM}}$ operation and analysis software was run to scan the surface roughness. There is a range of parameter that can be calculated using the software. The surface of each specimen was scanned (five measurements) to get the average surface area roughness. The data were collected in the form of scanned surface micrographs, maximum peak 
height (Sp), maximum valley height (Sv), root mean square of surface height (Sq), and arithmetical mean of the surface height (Sa). All roughness data were interpreted using SPSS software (Version 20, IBM, New York, NY 10022, USA) and two-way analysis of variance was used for statistical analysis.

\section{Nanoindentation testing}

Specimens were tested for hardness and elastic modulus using a Hysitron (TI 725 Ubi nanoindenter [Hysitron, Minneapolis, MN 55344, USA] containing a three-sided pyramidal Berkovich $142.3^{\circ}$ diamond probe) as described previously. ${ }^{[14]}$ The testing location was focused using an optical camera $(\times 10)$ and indentation was performed using a force of $2 \mathrm{~N}$. The indentation force and displacement of the load-unload cycle were used to calculate the absolute hardness. The elastic modulus was calculated using the value of reduced modulus (obtained from the nanoindentation system) and Poisson's ratio.

\section{RESULTS}

\section{Surface roughness}

To compare the surfaces roughness, the noncontact surface profilometry of roots was performed before and after root planing treatment. The data were collected in the form of scanned surface micrographs, maximum peak height (Sp), maximum valley height (Sv), root mean square of surface height (Sq), and arithmetical mean of the surface height (Sa). Characteristic micrographs comparing surface roughness profiles are shown in Figure 2.

In case of control group, the maximum surface peak height was recorded at $92 \mu \mathrm{m}$ whereas the maximum valley heights remained $132 \mu \mathrm{m}$ [Figure 2a]. The root planing treatment (both for Group 1 and 2) reduced the peak and valley heights, hence narrowing the difference between them [Figure $2 b$ and $c]$. The quantitative data comparing the effects of root planing treatment method on peak and valley heights have been presented in Figure 3. A clear trend observed in all study groups; the average maximum valley height (Sv) was higher than corresponding average maximum peak height (Sp). The average $S p$ and Sv for control groups remain $83.08 \pm 18.47 \mu \mathrm{m}$ and $117.58 \pm 18.02 \mu \mathrm{m}$, respectively. The root planning treatment in Groups 1 and 2 reduced average $\mathrm{Sp}$ and Sv significantly $(P<0.05)$. The $\mathrm{Sp}$ was reduced to $32.86 \pm 7.99 \mu \mathrm{m}$ and $62.11 \pm 16.07 \mu \mathrm{m}$ for Groups 1 and 2, respectively [Figure 3]. The Sv was reduced to $-49.32 \pm 29.51 \mu \mathrm{m}$ for Group 1 and $80.87 \pm 17.99 \mu \mathrm{m}$ for

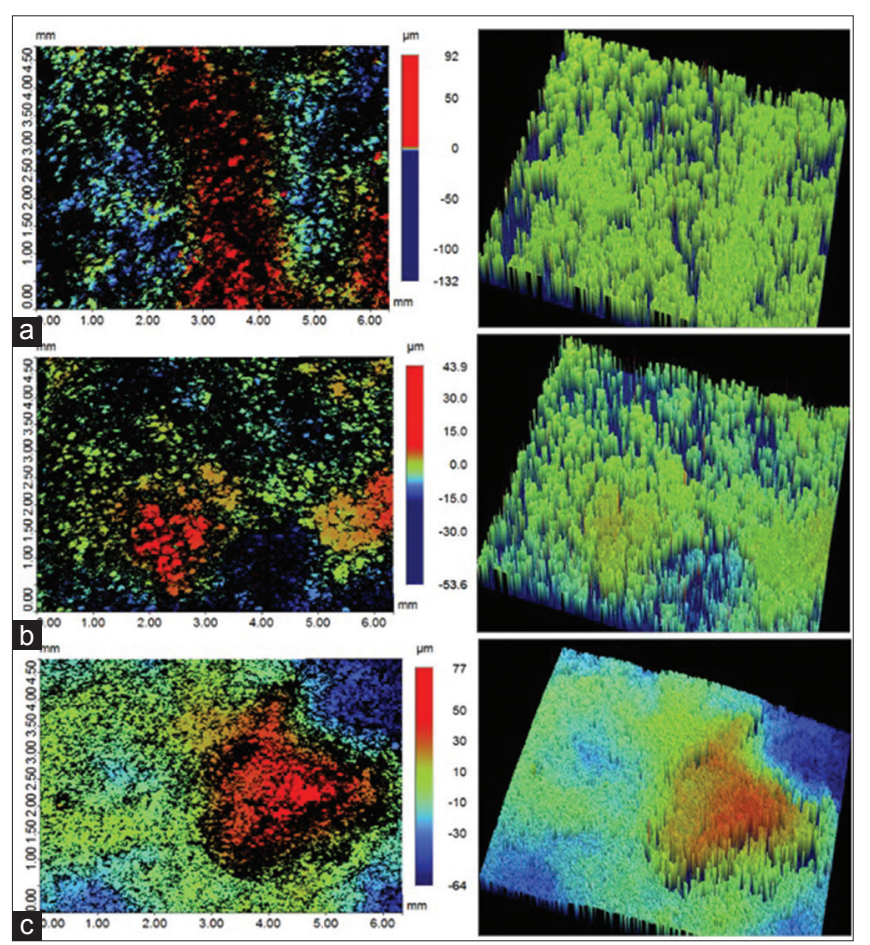

Figure 2: Representative surface roughness micrographs; (a) control (b) Group 1 (c) Group 2. Color-coded scale bar showing the range of surface peaks and valleys

Group 2. The Group 1 samples showed more decrease in the Sp and Sv compared to Group 2; however, the difference was not significant $(P>0.05)$.

The average of root mean square surface height (Sq) and arithmetical mean of the surface height (Sa) showed trends similar to Sp and Sv data. The Sa for the control group was $8.48 \pm 2.73 \mu \mathrm{m}$ and reduced to $3.09 \pm 0.72 \mu \mathrm{m}$ for Group 1 and $5.13 \pm 1.05 \mu \mathrm{m}$ for Group 2. The Sq values were generally higher than $\mathrm{Sa}$. The Sq for the control group was $12.61 \pm 3.78 \mu \mathrm{m}$ and reduced to $4.79 \pm 1.10 \mu \mathrm{m}$ for Group 1 and $7.10 \pm 1.13 \mu \mathrm{m}$ for Group 2 [Figure 4]. The root planing treatment (Groups 1 and 2) resulted in the reduction of surface roughness significantly $(P<0.05)$ as compared to the control group. Group 1 showed better surface roughness compared to Group 2; however, the difference was insignificant $(P>0.05)$.

\section{Nanoindentation}

The surface hardness and elastic modulus of cementum for the control group remain $0.28 \pm 0.13 \mathrm{GPa}$ and $5.09 \pm 2.67 \mathrm{GPa}$, respectively [Table 1]. The root planing treatment resulted in the increase in the hardness and elastic modulus, but changes remain insignificant. The hardness of cementum after root planing treatment was $0.37 \pm 0.16 \mathrm{GPa}$ and $0.44 \pm 0.18 \mathrm{GPa}$ for Groups 1 and 2, respectively [Table 1]. The elastic 


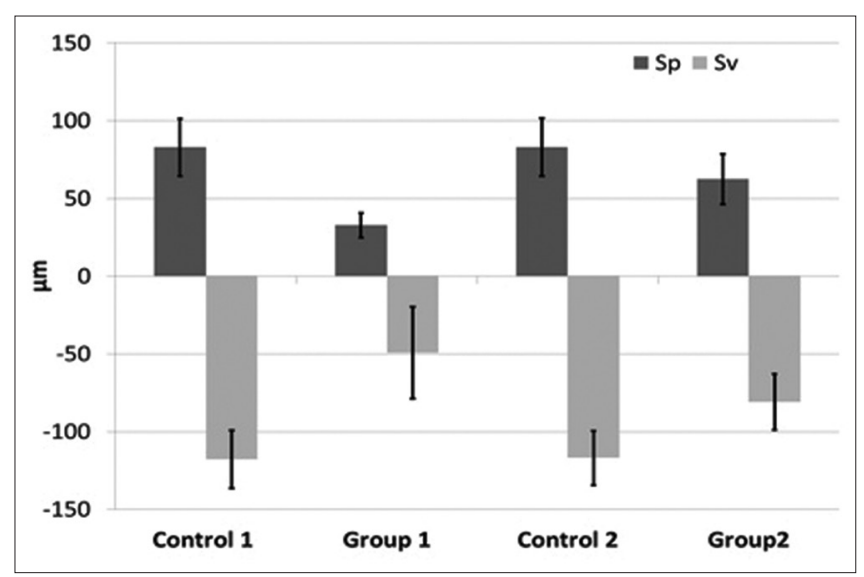

Figure 3: Comparison of maximum peak height $(\mathrm{Sp})$, maximum valley height (Sv) corresponding to various root planing treatments

\begin{tabular}{|c|c|c|}
\hline & Hardness (GPa) & Elastic modulus (GPa) \\
\hline Control & $0.28 \pm 0.13$ & $5.09 \pm 2.67$ \\
\hline Group 1 & $0.37 \pm 0.16$ & $6.32 \pm 2.70$ \\
\hline Group 2 & $0.44 \pm 0.18$ & $6.57 \pm 2.77$ \\
\hline
\end{tabular}

modulus of cementum after root planing treatment was increased to $6.32 \pm 2.70 \mathrm{GPa}$ and $6.57 \pm 2.77 \mathrm{GPa}$ for Groups 1 and 2, respectively.

\section{DISCUSSION}

Mechanical debridement using hand instruments and ultrasonic scalers plays a vital role in the management of periodontal diseases. In addition, smooth surface following mechanical debridement is essential to facilitate gingival fibrous tissue reattachment. ${ }^{[15]}$ The smooth root surfaces are of clinical significance such as easy to clean, prevent bacterial plaque redepositing and calculus formation. ${ }^{[16]}$ In addition to physiological tissues healing, surface features are also important for tissue regeneration. ${ }^{[5,17]}$

The efficiency of the scaling instrument to produce smooth surface is an important parameter. The current study has compared manual instruments (Gracey curettes) and ultrasonic scaler in terms of final surface smoothness following root planing. The surface roughness was significantly reduced following root planing treatment. Root surface cementum becomes rough due to uneven deposition of bacterial plaque and calculus and degeneration of cementum tissues. The mechanical debridement removes uneven calculus, pathological cementum and results in smoothening of root surface, hence reducing the surface roughness. ${ }^{[9,10]}$

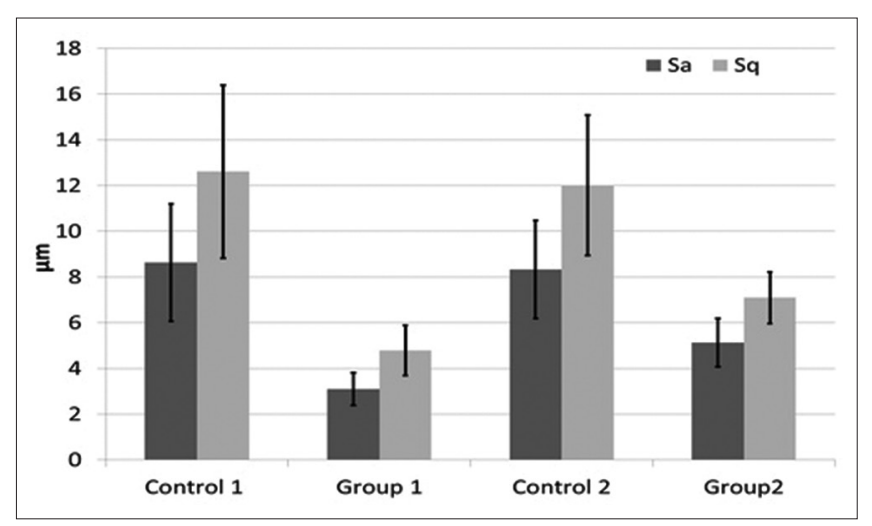

Figure 4: Comparison of root mean square of surface height $(\mathrm{Sq})$ and arithmetical mean of the surface height (Sa) corresponding to various root planing treatments

The Gracey curettes improved surface smoothness compared to ultrasonic scalers. This may be due to the fact that Gracey curettes facilitate better tactile proprioception and controlled movement to the operator. The ultrasonic instruments work on the principle of vibrational forces that may introduce new surface features following root planing. ${ }^{[18]}$ The concept that root surface features can be affected by various periodontal instruments is not new. A number of studies $^{[19]}$ suggested that hand instruments are more efficient in smoothening of the surface compared to ultrasonic instruments. On the other hand, a number of researches reported ultrasonic scalers better in terms of surface smoothening. ${ }^{[2]}$ In the current study, Gracey curettes reduced the surface roughness, maximum peak, and valley heights compared to untreated roots [Figures 2 and 3]. In terms of surface roughness, the ultrasonic scalers smoothened the surfaces slightly less efficient than Gracey curettes.

The cementum is a delicate tissue that covers the root part of tooth. The surface mechanical properties of cementum can be affected by various factors such as fluoride, moisture, and external forces. ${ }^{[21]} \mathrm{We}$ have compared the effects of manual and ultrasonic instrumentation on hardness and elastic moduli of cementum. The cementum hardness $(0.28 \pm 0.13 \mathrm{GPa})$ and elastic moduli $(5.09 \pm 2.67 \mathrm{GPa})$ that are in closely similar to hardness and elastic modulus previously reported for permanent teeth ${ }^{[22]}$ and deciduous teeth. ${ }^{[23]}$ These findings suggested that hardness and elastic modulus are not affected by periodontal diseases that are in agreement with the previous studies. ${ }^{[24]}$

The root planing treatment resulted in a minor increase in the hardness and elastic modulus of cementum. The removal of affected surface cementum may expose inner cementum or even root dentin and likely to 
increase the hardness and elastic modulus. ${ }^{[25]}$ The exposed surface may have variable inorganic contents hence altering the hardness; increase inorganic contents are known to reinforce the hardness and elastic moduli. ${ }^{[14,25]}$ Another contributory factor affecting the cementum hardness is moisture contents as drying can increase the hardness of cementum significantly. ${ }^{[21,25]}$ During the root planing, treatment on extracted teeth is likely to loss of moisture from the planed surfaces, hence increasing the hardness and modulus.

This is an in vitro study conducted using extracted teeth; hence, the exact simulation of the oral environment was not possible. Clinically, the complex oral environmental factors such as temperature, saliva, and $\mathrm{pH}$ can affect the functional efficacy of scaling instruments. Surface properties can easily be affected by a variety of variations such as technique, structural variations, operator factor, instrument designs, and manipulation. More clinical studies are needed to address these issues.

\section{CONCLUSIONS}

The Gracey curettes and ultrasonic scalers are capable of reducing roughness significantly following root planing treatment. Although Gracey curettes produced smoother surfaces than ultrasonic scalers, there was no significant difference. In terms of hardness and modulus of elasticity, periodontal diseases and root planing do not change significantly. Considering the known importance of root surface characteristics, any instrumentation that is likely to create excessively rough surface must be avoided. A uniformly smooth surface is likely to facilitate batter adhesion and healing of periodontal tissues following mechanical debridement.

\section{Financial support and sponsorship}

Nil.

\section{Conflicts of interest}

There are no conflicts of interest.

\section{REFERENCES}

1. Pihlstrom BL, Michalowicz BS, Johnson NW. Periodontal diseases. Lancet 2005;366:1809-20.

2. Deas DE, Moritz AJ, Sagun RS Jr., Gruwell SF, Powell CA. Scaling and root planing vs. conservative surgery in the treatment of chronic periodontitis. Periodontol 2000 2016;71:128-39.

3. Najeeb S, Khurshid Z, Zafar MS, Ajlal S. Applications of light amplification by stimulated emission of radiation (lasers) for restorative dentistry. Med Princ Pract 2016;25:201-11.

4. Esposito M, Grusovin MG, Coulthard P, Worthington HV. Enamel matrix derivative (Emdogain) for periodontal tissue regeneration in intrabony defects. Cochrane Database Syst Rev 2005; 2005(4):CD003875.

5. Zafar M, Khurshid Z, Almas K. Oral tissue engineering progress and challenges. Tissue Eng Reg Med 2015;12:387-97.

6. American Academy of Periodontology. Comprehensive periodontal therapy: A statement by the American Academy of Periodontology. J Periodontol 2011;82:943-9.

7. Cohen R, Mariotti A, Rethman M. Glossary of Periodontal Terms. Chicago: The American Academy of Periodontology; 2001.

8. Greenstein G. Nonsurgical periodontal therapy in 2000: A literature review. J Am Dent Assoc 2000;131:1580-92.

9. Hung HC, Douglass CW. Meta-analysis of the effect of scaling and root planing, surgical treatment and antibiotic therapies on periodontal probing depth and attachment loss. J Clin Periodontol 2002;29:975-86.

10. Bonito AJ, Lux L, Lohr KN. Impact of local adjuncts to scaling and root planing in periodontal disease therapy: A systematic review. J Periodontol 2005;76:1227-36.

11. Jacobson L, Blomlöf J, Lindskog S. Root surface texture after different scaling modalities. Scand J Dent Res 1994;102:156-60.

12. Zafar MS, Ahmed N. Nanoindentation and surface roughness profilometry of poly methyl methacrylate denture base materials. Technol Health Care 2014;22:573-81.

13. Alrahabi M, Zafar MS, Ahmed N. Effects of handpiece speed on the performance of undergraduate dental students in preclinical training. J Taibah Univ Med Sci 2015;10:50-5.

14. Zafar MS, Ahmed N. The effects of acid etching time on surface mechanical properties of dental hard tissues. Dent Mater J 2015;34:315-20.

15. Kishida M, Sato S, Ito K. Effects of a new ultrasonic scaler on fibroblast attachment to root surfaces: A scanning electron microscopy analysis. J Periodontal Res 2004;39:111-9.

16. Folwaczny M, Merkel U, Mehl A, Hickel R. Influence of parameters on root surface roughness following treatment with a magnetostrictive ultrasonic scaler: An in vitro study. J Periodontol 2004;75:1221-6.

17. Khurshid Z, Zafar M, Qasim S, Shahab S, Naseem M, AbuReqaiba A. Advances in nanotechnology for restorative dentistry. Materials 2015;8:717-31.

18. Pereira AH, Tirapelli $\mathrm{C}$, Rodolpho LA. Ultrasonic dental scaler performance assessment with an innovative cavitometer. Am J Appl Sci 2010;7:290.

19. Kerry GJ. Roughness of root surfaces after use of ultrasonic instruments and hand curettes. J Periodontol 1967;38:340-6.

20. Ritz L, Hefti AF, Rateitschak KH. An in vitro investigation on the loss of root substance in scaling with various instruments. J Clin Periodontol 1991;18:643-7.

21. Srivicharnkul P, Kharbanda OP, Swain MV, Petocz P, Darendeliler MA. Physical properties of root cementum: Part 3. Hardness and elastic modulus after application of light and heavy forces. Am J Orthod Dentofacial Orthop 2005;127:168-76.

22. Zafar MS, Ahmed N. Nano-mechanical evaluation of dental hard tissues using indentation technique. World Appl Sci J 2013;28:1393-9.

23. Zafar MS, Ahmed N. Nanomechanical characterization of exfoliated and retained deciduous incisors. Technol Health Care 2014;22:785-93.

24. Rautiola C, Craig R. The microhardness of cementum and underlying dentin of normal teeth and teeth exposed to periodontal disease. J Periodontol 1961;32:113-23.

25. HoSP, Goodis H, Balooch M, Nonomura G, Marshall SJ, Marshall G. The effect of sample preparation technique on determination of structure and nanomechanical properties of human cementum hard tissue. Biomaterials 2004;25:4847-57. 